UAM Vol. 28 Poznaí 2001

\title{
LITTÉRATURE
}

\author{
ALICJA BACZYK-TOMASZEWSKA
}

Université Adam Mickiewicz à Poznań

\section{GARCÍA SARAVÍ Y JUAN GOYTISOLO: EL CONCEPTO DEL TIEMPO}

\begin{abstract}
A bstract. Bączyk-Tomaszewska A licja, García Saravi y Juan Goytisolo: el concepto del tiempo [García Suraví and Juan Goytisolo: concept of time]. Studia Romanica Posnaniensia, Adam Mickiewicz University Press, Poznań, vol. XXVIII: 2001, pp. 103-115, ISBN 83-232-1144-2, ISSN 0137-2475.

The article is an attempt at a comparative analysis of texts by a contemporary Castillian writer, whose literary beginnings may be said to be rooted in the 1950s, and an Argentinean writer from La Plata, who belongs to the generation of the 1940s. What the two writers have in common is a worship of the word and similar subject matters, touching upon issues of universal character, such as life, death, the passage of time and the meaning of human existence. The thesis of the article is the following: the theme of the passage of time is the primary subject in the ocuvre of both representatives of Spanish literature. In the works of both the Argentinean and the Castillian writer there are clearly audible echoes of Gongota. Patterning themselves on Goya's pictures, especially his "Atrocities of War", the two use light and shadow in a similar way. Our aim was to make a comparative analysis of stylistic fealures of both artists and their method of crcating a poetic image. Noticing the visual character of the metaphors used, we proceeded in our analysis by a method of active reading on the syntactical and phonetic planes. Subject to analysis are selected sonnets of García Saraví and some essays and novels by Juan Goytisolo.
\end{abstract}

Vamos a tratar al poeta argentino de La Plata de la generación de poetas de los 40 y al narrador contemporáneo español de la llamada generación de los 50. ¿Cuáles son los objetivos nuestros? ¿Cuáles las causas que permiten la presente comparación?

El primer rasgo común es el culto a la palabra y el gran interés por la forma. El poeta argentino muestra influencias de Góngora, poeta barroco español. Lo mismo observamos en la obra de Juan Goytisolo cuyo estilo, según nuestra opinión, se caracteriza por el uso de conceptos y asociaciones de ideas, así como de contrastes típicos del estilo barroco. También la visualización de las metáforas aproxima a nuestros dos representantes de la lengua española en el aspecto del tipo de imaginación. Hablaremos más adelante de los métodos para crear la imagen visual así como la acústica. El manejo de luz y sombra y también el uso de „trompe l'oeil”, siendo el indicador del carácter pictórico del estilo de García Saraví y J. Goytisolo. Hay que 
observar que la agudez e ironía y también el humor negro con que pintan la sociedad evidencia su mutuo entusiasmo por Goya y su estilo realista hasta el extremo, algo tan español por otra parte. La construcción de las obras con el uso del recurso de las cajas chinas, (o sea de las distintas capas de sentido, la cual en consecuencia ofrece el retrato del artista en una época de crisis moral y quien por su parte se esconde vélazquianamente por detrás de los personajes qué están en el primer plano) es compartida por ambos.

La segunda causa que justifica nuestra comparación es el contenido. La obra de los dos 'hispanohablantes' muestra el interés por los temas eternos, los de la vida y la muerte, el problema del paso del tiempo ligado con ellos y del sentido de la existencia humana terrenal. La tesis que planteamos es la siguiente: el tema del paso del tiempo constituye la preocupación de los dos, de García Saraví y J. Goytisolo, por el destino humano, por la dimensión eterna de la vida y sus valores absolutos.

Nuestro análisis abarca el siguiente material:

- sonetos escogidos de Gustavo García Saraví

- ensayos y novelas escogidas de J. Goytisolo: Reivindicacionnes del conde don Julián 1970 (primera edición, México), Colo vedado 1985; Aproximaciones a Gaudí en Capadocia, 1990.

La reflexión a la cual nos lleva el análisis de la obra de García Saraví y la de Juan Goytisolo muestra con evidencia la interdependencia de la forma y del contenido. La larga trayectoria de la escritura de Juan Goytisolo trae consigo un cambio en la manera de escribir. El cambio del tono al hablar es muy claro; ¿cuál es el porqué de este cambio? ¿Sería a causa de la necesidad de crear un poco de ilusión artística, de enmascarar la realidad brutal? Juan Goytisolo suele escribir de una manera totalmente opuesta a la de Marcel Proust en cuanto a la diferencia entre 'ver' y 'el deseo de imitar'. El estilo de Juan Goytisolo en el tratamiento del tiempo y de su clase social es despiadado. El escritor español no tiene miedo de criticar a la burguesía, la estirpe social de la cual desciende hasta el punto de traicionarla, podemos observarlo en Reivindicación del conde don Julián donde el narrador se viste de personaje histórico que da título a la obra y quien dejó pasar a los árabes a la península ibérica dando así comienzo a la invasión árabe. Es frecuente y muy típico de Goytisolo esta estrategia literaria de contar una invasión que se desarrolla en varios estratos del texto: invasión en el plano del contenido y el de la forma. Esta segunda se realiza por medio del estrato fónico, hay que subrayar que el escritor habla con tono sarcástico y rebelde, poniendo en boca de su personaje-narrador, don Julián, un discurso acusador: 'tierra ingrata + entre todas espuria y mezquina + jamás volveré a tí." Aquí nos parece muy adecuada la característica del estilo de Marcel Proust, el gran maestro en el trato del problema del tiempo, observada por Walter Benjamin diciendo del gran escritor francés: „éste despiadado realista, privado de ilusión a quien le gustaba pasar, despojando su propio Yo del amor, de la moral, hace de su arte entero un disímulo para

\footnotetext{
'J. Goytisolo, Reivindicaciones del conde don Julión, ed. Seix Barral, Barcelona 1985, p. II
} 
éste único y más importante misterio de su clase social: el misterio económico. Aquí toma la voz Marcel Proust, aquí toma la palabra la brutalidad de la obra, habla la irreconciabilidad del hombre que se adelanta a su clase. Lo que el cumple, lo cumple como su maestro. $Y$ muchos aspectos de la grandeza de su obra esperarían el descubrimiento o el encuentro hasta que dicha clase, en la definitiva pugna, no diese muestra de sus rasgos más relevantes"2. Merece observar en este momento que el estilo de Juan Goytisolo es opuesto totalmente al de Marcel Proust. Goytisolo no habla en ese tono elegante del recuperador francés del tiempo perdido, su estilo es directo y lleno de crítica violenta dirigida hacia la clase de la cual el escritor provenía, es decir la burguesía acomodada.

De la misma manera en cuanto a nuestra comparación del narrador castellano con el argentino, debemos hacer una observación previa que es la siguiente: aunque les une la temática y el culto a la forma, son dos artistas distintos en cuanto al tono al hablar. García Saraví, el poeta platense, habla con un tono bajo, lleno de compasión y amor para sus compatriotas, algunas veces es una queja o un llanto; otras veces es ironía; por otra parte Juan Goytisolo usa tonos altos, unos sopranos, los cuales no respetan a nadie y que sin piedad recitan palabras violentas, llenas de grito estridente y hay que subrayar que este grito es especialmente una furia, el tono de la palabra de un artista rebelde, que no soporta ningún compromiso, su palabra está llena de odio. Podríamos denominar su estética, siguiendo a W. Benjamin, como la del 'schock', ya que el lector tiene que enfrentar unas situaciones realmente chocantes y fuera del orden del día. La estética de Gustavo García Saraví la denominamos como 'aurática', también tomando el criterio benjaminiano de evaluar el carácter de su lengua. Aquí debemos observar que en el Goytisolo más tardío, el de la época de sus ensayos, Aproximaciones a Gaudi en Capadocia, hay un cambio de estética del texto artístico y es necesario hacer la observación de que se trata de un texto literario y no periodístico pues en las entrevistas es siempre muy brutal y despiadado en cuanto a las observaciones de la realidad social, criticando severamente las instituciones. De esta manera en la capa estética de su texto literario de dicha etapa tardía encontramos un cambio muy claro del tono al hablar por el aurático, es decir, que el lector está invitado por el viajero barcelonés a contemplar el paisaje geográfico de Turquía, de Egipto y otras regiones de la zona del Mediterráneo, contemplar y observar dicho paisaje por la acción de la memoria y gracias al principio de correspondencia del sentimiento del narrador. Con esta realidad real - como dicho paisaje se vuelve una realidad artística, la del nuevo texto construído por dicho observador-narrador - viajero que viene desde Barcelona, al ver el relieve del terreno tiene la impresión que está soñando, ya que la estructura del paisaje le recuerda la arquitectura de Gaudí. Juan Goytisolo emplea la técnica del collage o del montaje del texto por medio de fragmentos de distintos textos, entre los cuales se encuentran algunos de otros escritores o poetas. Su método al construir el texto es el de citar palabras bellas y después

\footnotetext{
${ }^{2}$ W. Benjamin, Marcel Proust, en: Aniol historii, bajo la redacción de H. Orlowski.
} 
pasar al texto con imágenes sorprendentes Ilenas de surprise con cuyo uso se consigue sea chocar sea maravillar el gusto estético del lector. A esta estrategia se mantiene fiel en todas las épocas de su creación artística. En la etapa de transición, la de su trilogía compuesta por Señas de identidad, Reivindicaciones del conde don Julián y Juan sin tierra, podemos observar el fenómeno de la brutalización de la lengua, la cual se vuelve violenta, de acuerdo con el principio de que 'la violencia sólo se puede curar por la violencia ${ }^{3}$. Estas novelas fueron escritas en el extranjero, en París, fuera de la censura franquista; gracias a esta circunstancia el escritor pudo usar también el discurso crítico de la dictadura. En los ensayos, los de la última etapa de la escritura goytisoliana, hay numerosas descripciones de las calles de varias metrópolis de la región del Mediterráneo. Siempre en la calle hay mucho ruido y movimiento, la gente tiene prisa para atravesar la acera. Su manera de andar es comparada a la del ejercicio peatonal. A menudo hallaremos palabras cuyo campo semántico es el de la lucha: se trata de varios aspectos: la lucha instintiva del hombre vuelto animal (hombre animalizado, hombre - bestia feroz) o bien la lidia en un bello y umbroso campo. Estas imágenes están llenas de esperanza del cambio como algo positivo. La esperanza repercute en el del tiempo. Goytisolo utiliza el presente, pero se sobreentiende de que se trata del futuro.

A menudo el tema de la muerte y del paso del tiempo está desarrollado en unión con los problemas del taller del poeta. Nuestros representantes de la literatura española se preocupan contínuamente por la perfección de la forma, queriendo ser omnipotentes y totales. En J. Goytisolo son frecuentes las formas verticales y voluminosas (Aproximaciónes a Gaudi en Capadocia) de la creación posibles a través de la imaginación y filtrados por la memoria. Gustavo García Saraví, en el poema titulado sugestivamente Omnipotencia ${ }^{4}$ presenta una visión cósmica y clásica del poeta que quiere ser 'dueño del mundo'. Éste maneja 'como nadie los hilos de los títeres' y posee un 'infinito poder'. Puede 'dominar hábilmente los seres y circunstancias' y 'conseguir lo que quiere':

Parece ser que soy total, omnipotente,

dueño del mundo y que manejo como nadie los hilos de los títeres.

Todo lo puedo - casi todo - como un inca, un elefante, un niño rico.

Me dicen que domino hábilmente los seres $\mathrm{y}$ circunstancias que me rodean porque consigo lo que quiero: un dragón, un rubí, una amapola negra, caprichos varios, sólo con desearlos con garfios y puñales o inventados suspiros.

\footnotetext{
${ }^{3}$ Palabras de Juan Goytisolo, en una entrevista con él.

${ }^{4}$ G. García Saraví, Libro de quejas, en: op.cil., p. 232.
} 
El poder del poeta es comparable al de un animal feroz o un hombre salvaje - un elefante $o$ un inca. El poeta no está seguro de tener dichas calidades. Solamente 'parece' que las tiene y que puede todo. El poeta es su propietario de vez en cuando. En general no es su posesor y su sentimiento de impotencia es tan fuerte que, como dice, hasta, 'nadie se siente más desposeído que yo'. El lector de este poema puede observar el uso de la contraposición de las personas del diálogo: Yo/Nadie. El poeta habría preferido ser un hombre parecido a otra gente y cambiaría su fuerza de poeta por la de un hombre cualquiera:

Hoy, por ejemplo, cambiaría

mi infinito poder por una mosca,

una estampilla, un fósforo gastados,

un beso de los chicos.

Me cambiaría, digo por un hombre

que no te tenga,

para poder tenerte ${ }^{5}$.

Observemos el uso del pronombre posesivo 'te' que aparece dos veces y siempre con el verbo 'tener': en el contexto del poeta éste uso recibe el sentido de poseer el poder sobre su persona, la posibilidad de poder dominarse y decidir sobre sus actos. La facultad de escribir poemas se presenta a Gustavo García Saraví como algo menos importante que lo de ser un hombre verdadero, entonces todas las preciosidades de su talento no valen, son sólo caprichos. El acto de escritura de un poema trae frustración y engaño. Le proporciona al poeta: 'el miedo de conceder' a 'la hermosa palabra', 'esta reja de vocales y símbolos que engrilla con sonoras durezas la sencilla complicación de ser el otro lado de mí mismo"6.

El empleo del pronombre posesivo 'mi' permite resaltar la dura tarea del artista que se apena componiendo el poema: observemos la contraposición de 'mí mismo'/'mi página'. La página no escrita es 'un niño muerto', 'un fuego congelado'. Esta metáfora es muy evocadora se trata de que G. García Saraví considera que el mejor poeta es el que escribe de manera espontánea, con fe y ardor de niño. El niño muerto significa la falta de estas capacidades, lo peor que puede ocurrir cuando el poema espera su amanecer. Así revuelve el tema de la muerte. El acto de escritura simboliza para el poeta la vida, la felicidad $y$, a veces, la incapacidad de hacerlo; la muerte, es una sencilla complicación de ser el otro lado del poeta ${ }^{7}$.

No obstante, escribir resulta ser una necesidad, los poemas escritos constituyen una garantía de la inmortalidad del poeta quien está temorizado por recelar el olvido. Así nos dice:

No sé qué quedará

de mí, después de los olvidos.

\footnotetext{
5 Op. cit., p. 233.

${ }^{6}$ De la frustración y el engaño de las palabras y el soneto, p. 185.

7 Op. cit., p. 185.
} 
Ni de ti. Ni de nada, igual que los retratos

y las dedicatorias en los libros

y los amigos inmortales ${ }^{8}$.

G. Saraví se sirve del juego de los pronombres: 'mi/ ti' queriendo dar una perspectiva, un distanciamiento a su problema. Son los amigos los que serán 'inmortales' y no él. Del poeta quedarán algunos objetos: retratos y dedicatorias. El poeta se mira en el espejo del tiempo y ve su juventud que se le escapa, teme la falta de la memoria por parte de sus amores.

Observemos el uso del pronombre 'tu':

No sé tampoco si tu carácter,

tu interminable

(y aborrecible) juventud,

los alegres amores que te esperan

detrás de los adioses,

tendrán memoria para no olvidarse

de las memorias ${ }^{9}$.

El pronombre 'mi' cambia por 'nosotros' como para dar una dimensión más ancha al hecho de estar acompañado por el poema, ya el poeta no está solo, somos 'nosotros' y además está acompañado por la estrella del poeta francés quien le trae la gloria:

Entiendo, sin embargo,

que te confiere algún orgullo

creer que este poema, nosotros, nuestra anécdota,

son infinitos y perfectos

como estrellas de cine que se adoran

en plano americano.

Yo mismo pienso que estos días y sus laureles

son lo más tierno

que nos debíamos

con la vida ${ }^{10}$.

Para Juan Goytisolo la escritura significa el encuentro de paisajes solitarios - que son los paisajes de batalla por la escritura.

El texto de Juan Goytisolo es una permanente reflexión sobre el arte de escribir $y$, ante todo, sobre las circunstancias necesarias para que el acto de escritura pueda realizarse. La soledad, la libertad, el don de la imaginación activa y de la buena memoria - tales son las capacidades interiores del artista; la vida que lleva los hechos reales ofrece circunstancias exteriores tan necesarias a la recreación en el texto literario. El mismo Goytisolo ha dicho que en su escritura intervienen varios factores:

${ }^{8}$ Las hojas muertas, tardio poema de amor que no pretendo imitar al de Jacques Prévert, en:

G. García Saraví, op. cit., p. 223.

${ }^{9}$ Op. cit., p. 223.

${ }^{10}$ Op. cit., p. 224. 
La escritura de un texto supone la existencia de un fino entramado de relaciones entre los distintos nodulos que lo integran. Todo confluye en ella: acontecimientos ajenos, sucesos vividos, humores, viajes, casualidades, mediante su trabazón aleatoria con lecturas, fantasías e imágenes, en virtud de un ars combinatoria de cruces, correspondencias, asociaciones de la memoria, iluminaciones súbitas, corrientes alternas ${ }^{11}$.

La escritura del texto es un proceso consciente durante el cual el escritor debe atacar la materia literaria sirviéndose de medios lingüísticos. Juan Goytisolo trata la lengua como un arma en la lucha por la palabra. Al artista, durante el acto de escribir, se lo imagina como un luchador que enfrenta la realidad de escritura como el campo de batalla. Es aquí, en ese lugar fascinante donde el poeta vive plenamente por poder encontrar fuertes emociones y energías. La experiencia de dichas emociones no le hace đaño, el artista está acostumbrado a registrar los choques. La conciencia acostumbrada al registro del schock permite vencer los miedos y angustias curando su trauma juvenil. 'La función de la memoria - como leemos en Reik - es la de proteger las impresiones. El recuerdo conduce a su anulación. La memoria es en efecto conservadora, el recuerdo-destructivo" ${ }^{\prime 2}$ Reik, alumno de Freud, debió basar lo dicho sobre la tesis fundamental del padre del psicoanálisis segin la cual: "la conciencia aparece allí donde existe la huella del recuerdo ${ }^{-13}$. 'El sistema de conciencia tiene tal específica que el proceso de estimulación no causa en él un cambio duradero de elementos como ocurre en otros sistemas psíquicos sino que se desvanece por decirlo así en el fenómeno de la toma de la conciencia' ${ }^{14}$. «Los restos de los recuerdos son más 'claros y duraderos cuando el proceso no se hace conciente'. Como nos dice Benjamin 'la conciencia cumple la función de protección contra los estímulos' 15 . Estos estímulos funcionan bajo formas de energías destructoras que actúan desde fuera. El peligro que crean tiene forma de choques. Cuanto más está preparada la conciencia al registro de choques tanto menos puede aparecer la acción traumática del choque. Según la teoría psicoanalítica, la esencia del choque traumático yace en 'el corte de la protección delante la acción de los estímulos' ${ }^{16}$. El significado de espanto es la falta de 'preparación al sentimiento del susto'.

Freud, como es sabido, observaba los sueños y eran los sueños los que le suministraron material para sus investigaciones. En este caso se trata de la reconstrucción de la catástrofe la cual lleva a la neurosis. Estos sueños tienen una función terapéutica de apoderar el estímulo en el estado de miedo. Freud unía los experimentos sobre el funcionamiento de los mecanismos psíquicos con su propia creación y tal es también la circunstancia de Juan Goytisolo. En su libro autobiográfico Coto vedado, el

"J. Goytisolo, La Cuarentena, Ed. Mondadori España, Madrid 1991, p. 9.

${ }^{12}$ Citado por W. Benjamin, Sobre unos motivos en Baudelaire, Przegląd humanistyczny 5. 1970. p. 72.

13 Ibidem, p. 72.

14 Ibidem, p. 72.

15 Ibidem, p. 72.

${ }^{16}$ Ibidem, p. 73. 
escritor compara el acto de su escritura al viaje sentimental por el paisaje solitaro. El artista aparece bajo la imagen del culpable quien 'retorna siempre al sitio de su crimen'. ¿Por qué 'culpable’? Puede ser por eso de que el artista es responsable de sus acciones. Hay una corrida en el pueblo, metáfora de la lucha de la cual se trata en el texto. El artista se imagina ser un toreador 'inmerso en la masa bulliciosa o enardecida de aficionados' (lectores) 'venidos de todos los rincones de la provincia' con el objetivo de asistir en (como tú) 'la expiatoria y cruel ceremonia de los encierros', es decir en 'el acto de traer los torros a encerrar en el toril'; el poeta se encuentra encaramado en las talanqueras de la plazuela inferior de Elche de la Sierra por donde iban a irrumpir los bichos con su cortejo; 'irrumpir en medio de los gritos y estampidas de los petardos, aupamientos motivo de arrobo y entusiasmo de la abigarrada multitud; descolgarte del racimo humano para seguir calle arriba con tus amigos el tropel de los rezagados hacia la iglesia parroquial del pueblo; intentar prever por los chillidos y fugas precipitadas el regreso de los astados desde la plaza rectangular y vallada en donde horas después deberse celebrar la lidia y ejecución de los animales, el sangriento, colectivo ritual; internarte, al cabo de larga espera en el callejón atrancado, sordo al aviso del compañero albaceteño; longitud del trayecto hasta la iglesia, carencia de refugios y barreras; internarte en el callejón con el propósito de llegar al palenque en el que permanecen los toros; alcanzar la embocadura de la plaza; desde el portillo abierto en la empalizada de troncos verticales cerciorarte de la dificultad de entrar sin atraer la atención de uno de los bichos excitado por la detonación de las tracas, golpes y bastonazos; bicho rascar el suelo con las pezuñas y mirar tenazmente a la salida; bicho ansioso de embestir, cornear, vengarse de la cuadrilla de mozos que lo maltratan y burlan; buscar refugio a tu izquierda mientras la rez humillar el testuz y arrancar de súbito en dirección al postigo de la talanquera; dejar que pase; oir los gritos de terror cuando arremete a uno de ellos; echarlo por tierra; perseguir su furia persecutoria; abandonar (al hombre) de bruces como muerto; percibir de nuevo las voces y chillidos anunciadores de la irrupción del segundo toro; trepar a las talanqueras de la derecha de la bocacalle; arrimarte imprudentemente a la esquinera izquierda; (estar) arrinconado entre una pared y los troncos verticales de la empalizada'.

Juan Goytisolo, de mismo modo que García Saraví busca el camino de la perfección - el platónico en busca del Bien y de la Belleza. Es el camino de la iluminación. Es el viaje en busca de la luz. La luz mística, el misterio de la palabra. La palabra absoluta. El viaje en busca de los valores absolutos. Parece que está siguiendo la lección de los poetas de la generación del '98: 'Somos hijos de la tierra', 'Somos la misma tierra que siente y piensa ${ }^{\cdot 17}$.

Juan Goytisolo dice: 'SOY HIJO DE LA GUERRA'18. Expresándolo de esta manera propone su propia guerra 'con' y 'por medio' de las palabras. El objetivo de

\footnotetext{
${ }^{17}$ Las palabras de Pío Baroja.

${ }^{18}$ Coto vedado.
} 
dicha guerra es sobrevivir, traspasar los límites del tiempo y del espacio; escribir significa para él traspasar las fronteras, éstas visibles y aquellas invisibles, las del país o de los países o las del espíritu. El objetivo de la escritura del poeta platense era el mismo; podemos subrayar que los dos, tanto Gustavo García Saraví como Juan Goytisolo 'Tlevan la patria adentro' y esta patria es su lengua materna, el español.

El texto de Juan Goytisolo es una contínua lucha por la verdad de la palabra. Es una contínua búsequeda de la luz de la palabra y un peregrinaje por el fértil suelo linguístico. Una constancia es la abundancia de sinónimos que expresan la batalla: LUCHA - LID - BATALLA - GUERRA; una guerra de lenguajes tiene lugar en el texto de Juan Goytisolo. Por una parte, hay tendencia hacia el uso de las palabras cultas; por otra - de las coloquiales. Estas segundas aparecen en la Chanca, Juegos de manos, Señas de identidad que son novelas, mientras que en los ensayos y los libros de autobiografía (en páginas de creación, en el Coto vedado - en los pasajes en cursiva que manifestan la pura presencia del artista) aparecen las primeras. El escritor usa conscientemente varios estilos porque, según dice frecuentemente, la lengua tiene que ser abigarrada y representar el mestizaje cultural. La lengua es el crisol donde se juntan (y no se mezclan) varios estratos culturales: la sincronía y la diacronia. Podemos observar el espacio de la ciudad de Estambul como colisión de tiempos. Veamos cómo habla Juan Goytisolo. Citamos un fragmento que es testimonio de intertextualidad por parte de nuestro escritor quien funda su reflexión en las investigaciones del formalista ruso.:

En un sugestivo análisis de la «Semiótica de una ciudad», el célebre lingüista Iuri Lotman, padre de la escuela de Tartu, observaba que aquella, «en cuanto mecanismo semiótico complejo, generador de cultura, puede cumplir su misión en la medida en que encarna una fusión de textos y códigos heterogéneos, pertenecientes a lenguas y niveles distintos [...]. La arquitectura, los ritos y ceremonias de la urbe, su mismo plano, el nombre de las calles y de millares de otros vestigios de las épocas pretéritas aparecen como programas codificados que permiten producir de forma constante los textos de su historia. La ciudad es un mecanismo que engendra perpetuamente su propio pasado, el cual dispone así de la posibilidad de confrontarse con el presente de un modo prácticamente sincrónico. Bajo este concepto, la metrópolis, como la cultura, es un mecanismo que se opone al tiempo».

La yuxtaposición de planos históricos y étnicos de la gran urbe propicia desde luego la existencia y proliferación de colisiones espacio-temporales, fenómenos de hibridación y mezcla dinámica de discursos que representan a mis ojos el sello inequívoco de la modernidad. La pluralidad y convivencia de estilos, su contagio recíproco, el valor energético de la osmosis descentran la mirada del visitante, aniquilan su visión homogénea de las cosas, relativizan y fraccionan sus primeras impresiones globales. En las calles y lugares privilegiados de ese espacio-palimpsesto que es Estambul aquél permanece a la escucha de un texto políglota en el que una babel de lenguas - el lenguaje de las piedras - traza la historia incopósita de la ciudad fundada hace 27 siglos conforme a las indicaciones de un oráculo: el Bizancio-Constantinopla que, puesto bajo la protección de los dioses antes de encomendarse a la Trindad cristiana y elevar sus alminares esbeltos a la gloria del 
único, nos maravilla no sólo por su situación extraordinaria y esplendor de sus monumentos sino también por la riqueza de su semiótica, la sabia alternancia de sus juegos de sincronía y de diacronía ${ }^{19}$.

Más adelante Juan Goytisolo compara el espacio de la ciudad al de un bosque frondoso donde uno puede perderse. La visión del escritor sigue la estrategia habitual, desde lo fragmentario hasta lo complejo: 'la fragmentación de la visión general en una serie de secuencias dispersas, espacios discontínuos' ${ }^{20}$. Todo ello sirve a cambiar la mirada del visitante acostumbrado a la visión estereotipada de la ciudad que ofrecen los guías:

El conocimiento paulatino de las cosas sacude nuestras certidumbres momentáneas y las disloca como un seísmo: de la ciudad descrita en las guías, reproducida en los planos, compendiada paso a paso por el viajero que la recorre con aires de propietario surgen territorios aislados, sin conexión aparente, pero dotados de una fuerza escenográfica que hipnotiza y subyuga ${ }^{21}$.

El visitante de la ciudad esá comparado con un forastero. Nos permitimos hacer aquí una observación lingùística. ¿Por qué Juan Goytisolo escogió la palabra 'forastero'? y no la otra, por ejemplo 'visitante'? Sería a causa de la semejanza acústica de la palabra ‘forastero' a la palabra francesa ‘forêt?' Si tomamos la explicación como aceptable, podemos considerar que el escritor barcelonés está preparando de esta manera el ambiente de su tex to que yo calificaría de 'misterioso'. El lector que acompaña a nuestro forastero (él mismo pudiera ser este forastero) va domesticando poquito a poco el espacio de la ciudad. Va rastreándola calle por calle, barrio por barrio y en seguida le parece la ciudad de Estambul 'como un collage de tarjetas postales'. Podemos imaginar al visitante de la ciudad como un turista que está tomando fotos y que se aventura cada vez más lejos y por fin se pierde en el laberinto de las calles. Dicho estado del ánimo suyo lo describe Goytisolo del siguiente modo:

Desorientado, descentrado, atópico, me abandono a la estereofonía y diversidad de sus códigos, a la espesura y frondosidad que le otorgan historia y apetito de vida. ¡Las ramas, al fin, me impiden ver el bosque! El proceso ha sido largo pero enriquecedor. «Extraviarse en una ciudad, como se extravía uno en un bosque - decía Walter Benjamin - requiere en verdad toda una educación» 22 .

El lector se da cuenta, al adentrarse en el texto, que el forastero se vuelve narrador y que, por fin, dicho narrador es el mismo escritor! Y para que todo sea más o menos complicado, según el lector lo va a considerar, el mismísimo lector puede cumplir el papel de nuestro forastero, tanto la ilusión de viajar por el espacio imaginario del texto le deja llevar hasta nuevos horizontes del misterio de la palabra.

\footnotetext{
${ }^{19}$ En: Aproximaciones' a Gaudi en Capadocia, págs. 87-88.

${ }^{20}$ Ibidem, p. 88.

21 lbidem, págs. 88-89.

22 Ibidem, p. 89.
} 
Existen en Gustavo García Saraví descripciones parecidas de la ciudad" El poeta platense escribía sobre Buenos Aires nombrando sus calles, jugando con sus números, su forma, tratando la ciudad como su casa. Lo vemos claramente cuando habla de una calle que conduce al cementerio donde se encuentra la tumba de su madre:

Según se sabe,

La Plata tiene

calles con números

como las grandes capitales:

Azul, New York, Mercedes y otras.

Igual que una ruleta

con diagonales, jockeys, eucaliptus

$y$, sobre todo,

memorias de sus tardes con mateos, tranvías,

corsos de nardos y señores

que recuerdan los viejos: Benito Lynch, Mendióroz,

López Merino y los famosos médicos

Mengano y Perengano.

Igual que una ruleta,

explicaba, la calle 7

es colorada,

la 13 negra (por supuesto)

y la 21 colorada, como

la 38

y la 47 , con sus dulces naranjos

amargos.

Yo - pongamos por ejemplo - perduro

en 125 esquina

negro el 61 ,

lo que resulta divertido

y altamente azaroso. Claro está

que estas apreciaciones ( $y$ algunos nuevos nombres

que anoto: Petorutti, Ameghino, Speroni)

son subjetivas

y muchos habitantes-jugadores discuten

por el color de las arterias pares,

la diagonal 74

o si la Plaza cero es añil o verdosa.

De cualquier modo, sólo deseaba

mencionar al azar algunas cifras

y direcciones:

el poeta Mux vive

en colorado el 22, 
Rolando Venturini en negro el 8 y los cuarteles (utilísimos) cjuedan en la intersección de 51 negro y muchachito.

Y ya que estoy en este crucigrama no deseo olvidarme de otros signos: sección A, 2 y 124.

Es un lugar en las afueras. 2 y 124 negros, lógicamente.

Hay unos pocos árboles y es triste.

Queda en el cementerio. Allí yace enterrada

Mi pobre madre y ya, tal vez, un poco de mí mismo ${ }^{23}$.

Me ariesgo ahora a decir que Saraví intuyó el concepto del 'hombre-ciudad' el mismo que en Juan Goytisolo aparece claramente. ¿Qué quiere decir eso? El concepto del 'hombre - ciudad' significa una identificación del hombre con la ciudad; se trata de una comparación a la estructura de los organismos: el humano y el urbano. El hombre como organismo complicado con su biología y psicología y, también su historia; la ciudad - por su parte de igual modo un organismo estructurado, ante todo históricamente, pues también vivo y cambiante. Saraví nos dió una imagen metafísica de la provincia de Buenos Aires con todo lo pintoresco, comenzando por los bellos nombres de las pequeñas ciudades en el suburbio boaneriense: 'Azul', 'New York', 'Mercedes', pasando por los nombres de los coches de transporte público: „mateos" y llegando a recordar a la gente famosa que allí vive, novelistas, poetas, pintores, cuentistas. El factor del tiempo desempeña un gran papel en la vida, tanto en la del hombre como la de la ciudad. El poeta argentino lo subraya cuando recuerda a su madre fallecida la cual era su vida, ahora cuando ella está enterrada, un poco de el mismo yace en el cementerio.

Goytisolo describía los suburbios de Barcelona, llenos de vida. Cuando fueron destruídos para construir las casas nuevas, la ciudad perdió su antiguo aspecto y le pareció otra, entonces dijo que la Barcelona actual no es la misma que el había descrito en sus libros. Vemos pues que el tiempo desempeña un gran papel en la visión del mundo del poeta.

Hemos podido observar que el tiempo sirve a veces de circunstancia histórica o personal, su paso indica el fluir de la vida y los cambios. El juego con el tiempo, un intento de valorización y la tentación de absolutizarlo, otorgándole una importancia primordial en la creación del concepto del mundo- los dos representantes de la literatura española están de acuerdo en esta materia aunque llegan por otros caminos, pero no totalmente distintos. García Saraví fue poeta y Juan Goytisolo es narrador pero con talento dramático. Creó un teatro expiatorio donde al código inquisitorial

${ }^{23}$ G. García Saraví, Las calles de La Plata, cn: Libro de quejas, págs. 221-223. 
se junta el carnavalesco que parodia las ceremonias rituales castellanas. De este modo el escritor realiza su crítica de las instituciones sociales. Satiriza las costumbres, los ritos de la sociedad, su aspecto cruel, como éste de la corrida 'cruel ceremonia de los encierros' que son 'el acto de traer los toros a encerrar en el torril'. Juan Goytisolo subraya el aspecto festivo de dicha ceremonia y sufre identificándose con el destino de los animales. García Saraví, de modo parecido al de Juan Goytisolo, da mucha importancia al rasgo humano del texto. Cuando habla de los números de las calles recuerda a su madre. Expresa de este modo su deseo de regresar al origen. Las evocaciones del eterno retorno al principio de la civilización ibérica son también frecuentes en el texto de Juan Goytisolo. El toro es su símbolo más expresivo.

\section{BIBLIOGRAFIA}

Bussière-Perrın, A., Le théätre de l'expiation. Regards sur l'oetuve de rupture de Juan Goytisolo. Editions du CERS. Montpellier 1998.

Benjamin, W., Marcel Protst, [en:] Aniol historii, bajo la redacción de H. Orlowski, Poznań 1995.

B enjamin. W., Sobre unos molivos en Baudelaire. Przegląd Humanistyczny (Revista humanística) 5, Poznań 1970.

García Saraví. G., Obras completas, Empeño 14, Madrid 1981.

Goylisolo, J., Señas de identidad, Argos Vergara, S.A.Barcelona 1979.

Goyt is olo. J., Reivindicaciones del conde don Julián, Seix Barral, Barcelona 1985.

Goyt isolo, J., La Cuarentena, Mondadori, Madrid 1991.

Goytisolo, J., Aproximaciones a Gandi en Capadocia, Mondadori, Madrid 1990.

Guillên, C., Teorias de la historia literaria, Espasa Calpe, Madrid 1989.

Parkinson de Saz M., Sara „Introducción” en: Gustavo García Saraví. Obras completas, Empeño 14, Madrid 1981.

Zeidler-Jan iszewska A., „Drobne rysy w ciaglej katastrofie”, Instytut Kulturoznawstwa, Poznań 1991.

Joly Soldevilla, T., Panorama dit roman espagnol contemporain (1939-1975). CERS, Montpellier 1979. 